\title{
Origin of Oil
}

$\mathrm{T}$ HE United States Geological Survey and the American Petroleum Institute have, during the course of studies of source beds, amassed a wealth of data which may prove invaluable in the elucidation of the vexed problem of the origin of petroleum. Dr. P. D. Trask has made full use of this data, and in a recent paper (U.S. Department of the Interior, Prof. Paper 186-H) he explains inferences he has drawn, and suggests that they are worthy of the consideration of geologists interested in the problem.

Geological conditions under which petroleum is found point to its derivation chiefly from the organic matter of fine-grained marine sediments. The source of this organic matter is directly traceable to planktonic organisms in the overlying water. During their life, prior to burial in sediments, these plank. ton undergo successive chemical changes, and a study of these provides a valuable clue as to the constitution of the organic matter of sediments.

The main source of original organic matter is floating plant life which serves as food to the animal life of the sea. On being taken in as food, part of the plankton is assimilated in the tissues of the consuming organism, part is excreted as waste, and the rest is used to generate energy. That part which generates energy is destroyed during the process. The part which is excreted may again serve as food to some organisms, but it becomes successively less and less digestible. Ultimately there remains a complex residue of substances resistant to decomposition, and, broadiy speaking, this forms the organic constituents of sediments. After burial, this residue is associated with little if any free oxygen and, therefore, is unlikely to undergo much further alteration.

The average composition of marine plankton is approximately 24 per cent protein, 3 per cent fat, 73 per cent carbohydrates and other non-nitrogenous substances. The composition of the organic constituents of recent sediments is of the order of 40 per cent protein, 1 per cent fat and less than 60 per cent carbohydrates and other compounds. In ancient consolidated sediments, proportions are about 27 per cent protein, 1 per cent fat, and more than 60 per cent other compounds.

It is improbable that any substance present in organic constituents of sediments only in quantities of 1 per cent or less is a major source of oil. Cellulose is discredited on this count, since it is ordinarily found in recent sediments in amounts of 1 per cent or less. Other carbohydrates such as hemicellulose, starches and sugars, are found in equally small quantities and are accordingly discounted.

Proteins, since they form approximately 40 per cent of the organic matter of recent sediments and 27 per cent of that of lithified sediments, are possible sources of oil. The proteins in sediments, however, differ considerably from proteins of the original plankton whence they are derived. Simple proteins are present in recent sediments in such small quantities as to preclude their consideration as source materials.

Fats, though believed by many to be the chief sources of petroleum, are possibly not so, partly because they are present in insufficient quantity, and partly because they are unsaturated in character while the fats of petroleum are saturated.

In any event, cellulose, carbohydrates, simple proteins and fats together only form about 5 per cent of the organic constituents of sediments, and it is more probable that the remaining 95 per cent, or part of it, is responsible for the formation of petroleum. This is in point of fact an unassimilable residue composed of complex compounds deficient in oxygen. The tendency of buried organic constituents to come to chemical equilibrium might cause the generation of liquid hydrocarbons. These in turn might dissolve organic substances, and the resulting organic constituents in solution might react upon one another in order to reach a state of equilibrium. Repeated readjustments of this character might possibly result in the formation of petroleum.

To substantiate this hypothesis, however, detailed investigations of the chemical nature of the organic constituents of sediments are essential. Conclusions may then be reached as to the particular type of organic material likely to be transformed into oil by chemical reactions of the type envisaged.

\section{Studies of Metals and Alloys}

$\mathrm{O}^{\mathrm{F}}$ the papers read or taken as read at the Autumn Meeting of the Institute of Metals at Sheffield on September 6-9, the following short abstracts of some of the more generally interesting will give an indication of the widely varying fields of research considered.

In view of the engineering importance of alloys, both ferrous and non-ferrous, which consist of two phases of appreciably different hardnesses and of inclusions in metals generally, a paper by Hermann Unckel, on the deformation of the macrostructure of some two-phase alloys by cold-rolling, is welcome. Although this is but the first stage in the con- sideration of the subject, the paper gives much interesting data, and cannot fail to arouse the interest of metallographers generally.

Inverse segregation, that is, the segregation of components in an alloy in the reverse direction to that which would normally be expected, is a matter of both academic and practical importance. N. B. Vaughan contributes a general review of the present position, together with an extensive bibliography which will be widely appreciated.

The transformation which occurs at a tempera. ture of about $470^{\circ} \mathrm{C}$. in the $\beta$-brass and which has been known now for some forty years, is dealt with 